\title{
Interaction between GSTM1/GSTT1 Polymorphism and Blood Mercury on Birth Weight
}

\author{
Bo-Eun Lee, ${ }^{1}$ Yun-Chul Hong, ${ }^{2}$ Hyesook Park, ${ }^{1}$ Mina Ha, ${ }^{3}$ Bon Sang Koo, ${ }^{4}$ Namsoo Chang, ${ }^{5}$ Young-Man Roh, ${ }^{6}$ \\ Boong-Nyun Kim, ${ }^{7}$ Young-Ju Kim, ${ }^{8}$ Byung-Mi Kim, ${ }^{1}$ Seong-Joon Jo, ${ }^{9}$ and Eun-Hee $\mathrm{Ha}^{1}$
}

${ }^{1}$ Department of Preventive Medicine, School of Medicine, Ewha Woman's University, Seoul, Korea; ${ }^{2}$ Department of Preventive Medicine, Seoul National University College of Medicine, Seoul, Korea; ${ }^{3}$ Department of Preventive Medicine, Dankook University College of Medicine, Cheonan, Korea; ${ }^{4}$ Department of Obstetrics and Gynecology, Ulsan University Hospital, University of Ulsan College of Medicine, Ulsan, Korea; ${ }^{5}$ Department of Nutritional Science and Food Management, Ewha Woman's University, Seoul, Korea; ${ }^{6}$ Institute of Environmental and Industrial Medicine, Hanyang University, Seoul, Korea; ${ }^{7}$ Division of Child and Adolescent Psychiatry, Department of Psychiatry and Institute of Human Behavioral Medicine, Seoul National University College of Medicine, Seoul, Korea; ${ }^{8}$ Department of Obstetrics Medicine, School of Medicine, Ewha Woman's University; ${ }^{9}$ Ministry of Environment, Division of Environmental Health Policy, Gwacheon, Korea

BaCKGround: Mercury $(\mathrm{Hg})$ is toxic to both the reproductive and nervous systems. In addition, glutathione $S$-transferases (GSTs), which conjugate glutathione to a variety of electrophilic compounds, are involved in the detoxification of $\mathrm{Hg}$.

OвJестіVE: In this study we examined the association between prenatal exposure to $\mathrm{Hg}$ and birth weight as well as the influence of GST polymorphisms.

METHODS: The total $\mathrm{Hg}$ concentration in maternal and cord blood was measured from 417 Korean women and newborns in the Mothers and Children's Environmental Health study from 2006 to 2008. Information on birth weight was collected from the patients' medical records. The genotyping of glutathione $S$-transferase M1 (GSTM1) and glutathione $S$-transferase T1 (GSTT1) polymorphisms was carried out using polymerase chain reaction. Regression analysis was performed to determine the association between the blood $\mathrm{Hg}$ concentration and birth weight in mothers with GSTM1 and GSTT1 polymorphisms.

RESULTS: The geometric mean levels of $\mathrm{Hg}$ in the maternal blood during late pregnancy and in cord blood were $3.30 \mu \mathrm{g} / \mathrm{L}$ and $5.53 \mu \mathrm{g} / \mathrm{L}$, respectively. For mothers with the GSTT1 null genotype, elevated $\mathrm{Hg}$ levels in maternal blood during late pregnancy were associated with an increased risk of lower birth weight. For mothers with both GSTM1 and GSTT1 null genotype, both maternal and cord blood $\mathrm{Hg}$ levels were associated with lower birth weight.

ConCLUSIONS: This study suggests that the interactions of $\mathrm{Hg}$ with GSTM1 and GSTT1 polymorphisms play a role in reducing birth weight.

KEY WORDS: birth weight, GSTM1, GSTT1, mercury, polymorphism, pregnancy. Environ Health Perspect 118:437-443 (2010). doi:10.1289/ehp.0900731 available via http://dx.doi.org/ [Online 23 October 2009]

Mercury $(\mathrm{Hg})$ is ubiquitous in the global environment with both natural and anthropogenic origins (Gundacker et al. 2007; Oken and Bellingerb 2008). There has been increasing concern regarding the detrimental effects of $\mathrm{Hg}$ on human health (Counter and Buchanan 2004). Hg has toxic effects on a wide variety of systems, particularly the central nervous system, kidneys, and skin (Brodsky et al. 1985). Moreover, exposure to methylmercury $(\mathrm{MeHg})$ can have neurotoxic effects through oxidative stress (Castoldi et al. 2001). In particular, pregnant women, fetuses, and infants are quite susceptible to the toxic effects of $\mathrm{Hg}$ (Jedrychowski et al. 2006; Trasande et al. 2005). Previous studies have reported that intrauterine exposure to total $\mathrm{Hg}$ is associated with neurobehavioral dysfunction in children (Jedrychowski et al. 2006; Lederman et al. 2008).

In addition, the reproductive toxicity of $\mathrm{MeHg}$ and $\mathrm{Hg}$ vapor has been confirmed in many animal studies (Beyrouty and Chan 2006; Fredriksson et al. 1993; Morgan et al. 2002). In humans, several studies have reported a relationship between occupational
$\mathrm{Hg}$ exposure and adverse reproductive outcomes, such as spontaneous abortion, growth retardation, congenital malformation, and fetal death (Seidler et al. 1999; Sikorski et al. 1987). However, studies examining $\mathrm{Hg}$ exposure in relation to birth weight have shown conflicting results. Some studies have reported an inverse association between the birth weight and the $\mathrm{MeHg}$ concentration in maternal and cord blood (Foldspang and Hansen 1990) and total $\mathrm{Hg}$ levels in the newborn and maternal hair (Sikorski et al. 1986; Xue et al. 2007), whereas others have shown no such association (Grandjean et al. 2001; Lederman et al. 2008; Lucas et al. 2004; Marques et al. 2008). This variability may be mediated partly by genetic variations.

It has been suggested that glutathione $(\mathrm{GSH})$ plays an important role in $\mathrm{Hg}$ metabolism (Custodio et al. 2005). Both inorganic $\mathrm{Hg}$ and $\mathrm{MeHg}$ bind to $\mathrm{GSH}$, possibly through a process catalyzed by glutathione $S$-transferase (GST) (Engström et al. 2008; Gundacker et al. 2007), and stable GSH-metal conjugates are eliminated in the feces and urine (Ballatori 2002; Ballatori and
Clarkson 1985). GSTs are phase II xenobiotic metabolizing enzymes that catalyze the conjugation of a variety of electrophilic compounds with GSH (Hayes and Strange 2000). Glutathione $S$-transferase M1 (GSTM1) and glutathione $S$-transferase T1 (GSTT1) genes are polymorphic in the human population (Schneider et al. 2004; Wormhoudt et al. 1999). GSTM1 and GSTT1 null genes are the result of two homozygous deletions that result in a loss of functional activity (Jain et al. 2006). However, there is inconsistency in the relationship between GSTT1 and GSTM1 polymorphisms and $\mathrm{Hg}$ level. Gundacker et al. (2007) reported that the double-deleted homozygous genotypes for GSTT1 and GSTM1 were associated with a higher hair $\mathrm{Hg}$ levels, whereas the GSTM1/GSTT1 genotype was not related to the retention of $\mathrm{MeHg}$, as measured by the erythrocyte total $\mathrm{Hg}$ or inorganic $\mathrm{Hg}$ in the whole blood, plasma, and urine (Custodio et al. 2004, 2005).

On the other hand, $\mathrm{Hg}$ exposure causes oxidative stress through the formation of free radicals or an alteration of the antioxidant capacity of cells (Hussain et al 1997; Lund et al. 1993), and Hg-induced oxidative stress might interfere with normal intrauterine growth (Kim et al. 2005). However, GSH may scavenge the reactive oxygen species generated by $\mathrm{Hg}$ exposure (Pinheiro et al. 2008), and the GSTM1 (Park et al. 2008) and GSTT1 (Dusinská et al. 2001) null genotypes have been associated with increased oxidative stress.

To date, the relationships among Hg exposure, birth weight, and GST polymorphisms have not yet been examined. Therefore, this study examined whether a GST polymorphism can modify the association between intrauterine $\mathrm{Hg}$ exposure and birth weight.

Address correspondence to E. Ha, 911-1 Mok-6dong, Yangcheon-ku, Seoul, Korea. Telephone: 82-2-2650-5757. Fax: 82-2-2653-1086. E-mail: eunheeha@ewha.ac.kr

This study was supported by the Mothers and Children's Environmental Health project of the Ministry of Environment, Republic of Korea.

The authors declare they have no competing financial interests.

Received 27 February 2009; accepted 23 October 2009 


\section{Materials and Methods}

Study population and data collection. This study is based on the Mothers and Children's Environmental Health (MOCEH) study, which is a multicenter prospective cohort study. The MOCEH study has been carried out since 2006 to determine the effects of maternal environmental exposure on fetal and postnatal growth or development. All pregnant women living in the targeted study site (i.e., Seoul, Cheonan, and Ulsan) who are in the first trimester of pregnancy at the time of approved by the institutional review boards at Ewha Woman's University (Seoul), Dankook University Hospital (Cheonan), and Ulsan University Hospital (Ulsan, South Korea), and written informed consent was obtained from each woman. screening are eligible. The study protocol was

At the time of this study, 957 pregnant women were enrolled in the MOCEH study, and the pregnancy outcomes of 629 women were followed up. The study subjects were restricted to those for whom maternal and cord blood Hg levels and GSTM1/GSTT1 genotype were assessed. Overall, 445 participants were eligible for this study. Of these 445 women, the following subjects were excluded: 14 with multiple births, 1 with stillbirth, 1 whose infant had a congenital anomaly, and 12 who had preeclampsia or gestational diabetes mellitus. Finally, 417 pregnant women were enrolled in the analysis.

Data collection consisted of an interviewed questionnaire, nutritional survey, and biological samples (blood and urine). Information on sociodemographic characteristics, prior medical history, psychosocial status,

Table 1. Characteristics of the mothers and infants.

\begin{tabular}{|c|c|c|c|c|}
\hline \multirow[b]{2}{*}{ Characteristic } & \multirow[b]{2}{*}{$n(\%)$} & \multicolumn{2}{|c|}{ Birth weight (g) } & \multirow[b]{2}{*}{$p$-Value } \\
\hline & & Mean & $95 \% \mathrm{Cl}$ & \\
\hline \multicolumn{5}{|c|}{ Maternal characteristics } \\
\hline \multicolumn{5}{|l|}{ Age (years) } \\
\hline$<30$ & $187(44.8)$ & 3313.0 & $3250.6-3375.5$ & \multirow[t]{3}{*}{0.22} \\
\hline 30 to $<35$ & $178(42.8)$ & 3273.9 & $3217.7-3330.0$ & \\
\hline$\geq 35$ & $52(12.5)$ & 3200.6 & 3057.3-3343.8 & \\
\hline \multicolumn{5}{|c|}{ Prepregnancy BMI $\left(\mathrm{kg} / \mathrm{m}^{2}\right)$} \\
\hline$<18.5$ & $55(13.3)$ & 3170.5 & $3073.4-3267.5$ & \multirow[t]{3}{*}{0.02} \\
\hline 18.5 to $<23.0$ & $233(56.4)$ & 3274.4 & 3222.6-3326.2 & \\
\hline$\geq 23.0$ & $125(30.3)$ & 3361.2 & $3277.6-3444.8$ & \\
\hline \multicolumn{5}{|l|}{ Education (years) } \\
\hline$<12$ & $135(33.7)$ & 3275.7 & 3197.9-3353.4 & \multirow[t]{2}{*}{0.94} \\
\hline$\geq 12$ & $265(66.3)$ & 3279.0 & 3229.3-3328.7 & \\
\hline \multicolumn{5}{|c|}{ Fish consumption (g/day) } \\
\hline$\leq 150$ & $344(90.0)$ & 3267.3 & $3221.8-3312.9$ & \multirow[t]{2}{*}{0.17} \\
\hline$>150$ & $39(10.0)$ & 3367.1 & $3230.1-3504.0$ & \\
\hline \multicolumn{5}{|l|}{ GSTM1 } \\
\hline Present & $169(40.5)$ & 3289.6 & $3225.2-3353.9$ & \multirow[t]{2}{*}{0.77} \\
\hline Null & $248(59.5)$ & 3277.3 & $3224.5-3330.2$ & \\
\hline \multicolumn{5}{|l|}{ GSTT1 } \\
\hline Present & $195(46.8)$ & 3262.8 & 3199.4-3326.1 & \multirow[t]{2}{*}{0.37} \\
\hline Null & $222(53.2)$ & 3299.4 & $3246.6-3352.3$ & \\
\hline \multicolumn{5}{|c|}{ Infant characteristics } \\
\hline \multicolumn{5}{|l|}{ Sex } \\
\hline Male & 207 (49.6) & 3315.8 & 3253.9-3377.6 & \multirow[t]{2}{*}{0.11} \\
\hline Female & $210(50.4)$ & 3249.3 & $3196.1-3249.3$ & \\
\hline \multicolumn{5}{|l|}{ Parity } \\
\hline 0 & $109(28.1)$ & 3292.7 & 3215.6-3369.8 & \multirow[t]{3}{*}{0.99} \\
\hline 1 & $177(45.6)$ & 3287.9 & $3218.6-3357.2$ & \\
\hline$\geq 2$ & $102(26.3)$ & 3282.8 & $3211.6-3354.1$ & \\
\hline \multicolumn{5}{|c|}{ Gestational age (weeks) } \\
\hline$<37$ & $14(3.4)$ & 2512.1 & 2168.3-2855.9 & \multirow[t]{2}{*}{$<0.01$} \\
\hline$\geq 37$ & $403(96.6)$ & 3309.0 & 3270.8-3347.3 & \\
\hline \multicolumn{5}{|l|}{ Birth weight (g) } \\
\hline$<2,500$ & $7(1.7)$ & 2074.3 & 1513.4-2635.2 & \multirow[t]{2}{*}{$<0.01$} \\
\hline$\geq 2,500$ & 410 (98.3) & 3302.9 & $3265.2-3340.7$ & \\
\hline
\end{tabular}

Numbers within subgroups vary slightly because of missing values for some variables.

Table 2. GMs and percentiles of total $\mathrm{Hg}$ concentration $(\mu \mathrm{g} / \mathrm{L})$ in maternal and cord blood.

\begin{tabular}{llllllll}
\hline \multirow{2}{*}{ Sample } & & & \multicolumn{5}{c}{ Percentile } \\
\cline { 5 - 8 } & GM & Range & 10th & 25th & 50th & 75th & 90th \\
\hline Maternal blood & & & & & & & \\
$\quad$ Early pregnancy & 3.67 & $0.27-22.6$ & 1.79 & 2.59 & 3.85 & 5.20 & 6.65 \\
Late pregnancy & 3.30 & $0.12-18.5$ & 1.80 & 2.45 & 3.23 & 4.45 & 6.27 \\
Cord blood & 5.53 & $0.23-24.1$ & 3.10 & 4.19 & 5.54 & 7.59 & 9.57 \\
\hline
\end{tabular}

health behavior, and environmental exposure was collected from an interview with trained nurses. Gestational age was estimated based on the onset of the last menstrual period; if the last menstrual period was unreliable or if there was a significant discordance between the ultrasonographic and last menstrual period dating (> 10 days), the first ultrasonographic estimation of the gestational age was used. Trained nurses in the delivery room routinely measured birth weight using a digital scale at birth and recorded it on the patient's medical charts. Information on the birth outcome, such as birth weight, gestational age, parity, and infant sex, was collected from the medical records at delivery. A dietary assessment based on 24-hr recall of dietary intake on the day before the blood test was administered within 20 gestational weeks. The food and nutrient intake, including the amount of fish consumption, was assessed using a computerized nutrient-intake assessment software program (CAN-Pro 3.0; Korean Nutrition Society, Seoul, Korea).

$\mathrm{Hg}$ analysis. The maternal blood samples were obtained during early pregnancy (12-20 gestational weeks) and late pregnancy (28-42 gestational weeks). The cord blood samples were collected at birth. The blood samples were stored at $-70^{\circ} \mathrm{C}$ until analysis. $\mathrm{Hg}$ analysis was performed by flow injection coldvapor atomic absorption spectrometry (AAS) (DMA-80; Milestone, Bergamo, Italy). The sample was initially dried in an oxygen stream passed through a quartz tube located inside a controlled heating coil. The combustion gases were further decomposed on a catalytic column at $750^{\circ} \mathrm{C}$. $\mathrm{Hg}$ vapor was collected on a gold amalgamation trap and then desorbed for quantification. The $\mathrm{Hg}$ content was determined by AAS. The laboratory analyses were carried out using standardized qualitycontrol procedures. An internal control was used for each series of analyses. The precision and accuracy of the $\mathrm{Hg}$ level measurement were verified by periodically participating in an external quality control program (interlaboratory calibration exercises). The limit of detection (LOD) was $0.158 \mu \mathrm{g} / \mathrm{L}$, and no sample had an $\mathrm{Hg}$ level below the LOD.

Genotyping of GSTM1 and GSTT1. The genomic DNA was extracted from the whole blood using a QIAamp DNA blood kit (Qiagen, Valencia, CA, USA). GSTM1 and GSTT1 polymorphisms were genotyped using a polymerase chain reaction (PCR) approach. As a positive control, coamplification of the 268-bp fragment of the $\beta$-globin gene was performed at the same time as the analysis of the GSTM1 and GSTT1 polymorphisms. The PCR mixture $(20 \mu \mathrm{L})$ for GSTM1 and GSTT1 genotyping contained $10 \mathrm{mM}$ Tris- $\mathrm{HCl}(\mathrm{pH}$ 9.0), $40 \mathrm{mM} \mathrm{KCl}, 1.5 \mathrm{mM} \mathrm{MgCl}_{2}, 0.25 \mathrm{mM}$ of each dNTP, 1 unit Taq polymerase 
(Bioneer, Seoul, Korea), 20 pmol of the forward and reverse primers, and 50-100 ng of the genomic DNA as a template. The following primer sets for the GSTM1 and GSTT1 genes were used for the amplification reaction: 5'-GAACTCCCTGAAAAGCTAAAGC-3' (forward) and 5'-GTTGGGCTCAAA TATACGGTGG-3' (reverse) for GSTM1, and 5'-TCACCGGATCATGGCCAGCA-3' (forward) and 5'-TTCCTTACTGGTCC TCACATCTC-3' (reverse) for GSTT1. The amplifications were performed under the following conditions: initial denaturation at $94^{\circ} \mathrm{C}$ for $5 \mathrm{~min} ; 35$ cycles of denaturation at $94^{\circ} \mathrm{C}$ for $1 \mathrm{~min}$, annealing at $65^{\circ} \mathrm{C}$ for $1 \mathrm{~min}$, and extension at $72^{\circ} \mathrm{C}$ for $1 \mathrm{~min}$; and a final extension at $72^{\circ} \mathrm{C}$ for $7 \mathrm{~min}$. PCR amplification of the reaction mixtures was carried out using a PTC-200 thermal cycler (MJ Research, Watertown, MA, USA).

To evaluate the PCR-amplified fragments, electrophoresis on 3\% 3:1 NuSieve/agarose gel was used (Cambrex Bio Science, Rockland, ME, USA). Genotyping of the GSTM1 and GSTT1 genes was performed based on the presence of a 215-bp product and 459-bp product, respectively. The null genotype was defined as a homozygous deletion of the gene. To confirm the analyses, $10 \%$ of the samples were selected randomly and genotyped again, with identical results.

Statistical analysis. Descriptive analyses were given for characteristics of the study subjects, and birth weight according to maternal and infant characteristics was evaluated using $t$-test or analysis of variance. After descriptive analyses, $\mathrm{Hg}$ concentrations were transformed logarithmically because of their skewed distribution. The geometric means (GMs) and percentiles for $\mathrm{Hg}$ concentrations were calculated. The relationship between $\mathrm{Hg}$ concentration and risk factors were examined using a Wilcoxon ranksum test or Kruskal-Wallis rank sum test.
We used regression analysis to examine the effects of $\mathrm{Hg}$ levels in the maternal and cord blood on the birth weight in mothers with the GSTM1 or GSTT1 genotype. The covariates in the multiple regression models were chosen as follows: First, the risk factors associated with $\mathrm{Hg}$ exposure or birth weight were identified from the literature. Second, the variable was considered to be a potential confounder if the variables were related to birth weight or $\mathrm{Hg}$ level at $p<0.20$ in univariate analyses. Covariates included the indicator variables for infant sex, maternal age $(<30,30$ to $<35$, $\geq 35$ years), prepregnancy body mass index (BMI; < 18.5, 18.5 to $<23, \geq 23 \mathrm{~kg} / \mathrm{m}^{2}$ ), maternal educational level $(<12, \geq 12$ years $)$, parity $(0,1, \geq 2)$, and continuous variables for gestational age (weeks) and weight gain (kilograms). In addition, information on amalgam fillings was collected, but there was no correlation between the presence of amalgam fillings and blood $\mathrm{Hg}$ levels. Therefore, amalgam fillings were not included in the analyses. Some participants had missing data for a particular variable and were excluded from multivariate analysis. To examine interactive effect of the genotypes and $\mathrm{Hg}$ on birth weight, we included an interaction term between $\mathrm{Hg}$ level and genotypes in the multivariate analysis. After identifying the interaction effect, stratified analysis was performed by genotypes of GSTM1/GSTT1, and combined effects of GSTM1 and GSTT1 genotype were also assessed using regression analysis.

In the generalized linear model, analysis of covariance was carried out for birth weight, and the least-square mean of birth weight according to GSTM1 and GSTT1 polymorphism and $\mathrm{Hg}$ level was estimated. The average $\mathrm{Hg}$ level during pregnancy was divided into three categories according to a tertile distribution, and GSTM1/GSTT1 genotype was classified as both present, either null, and double null. All statistical analyses were carried out using SAS statistical software (version 8.2; SAS Institute Inc., Cary, NC, USA).

\section{Results}

All participants were of Korean ethnicity. The mean maternal age was 30.1 years, and $66.3 \%$ of the participants had completed $>12$ years of education. The prevalence of the null genotype for GSTM1 and GSTT1 was $59.5 \%$ and $53.2 \%$, respectively. The mean \pm SD birth weight for newborns was 3,282 $\pm 433 \mathrm{~g}$. Approximately $97 \%$ of the infants were born at term. The birth weight increased with increasing BMI at prepregnancy and gestational age (Table 1).

Table 2 shows the distribution of $\mathrm{Hg}$ concentrations. The GM of the maternal blood $\mathrm{Hg}$ concentration was $3.67 \mu \mathrm{g} / \mathrm{L}$ during early pregnancy and $3.30 \mu \mathrm{g} / \mathrm{L}$ during late pregnancy. The levels of cord blood $\mathrm{Hg}$ were higher than the concentration of maternal blood $\mathrm{Hg}$.

$\mathrm{Hg}$ levels in the cord blood correlated with that in the maternal blood during late pregnancy (Pearson $r=0.72, p<0.0001$ ). When we analyzed the relationship between maternal and cord blood according to GSTM1 and GSTT1 genotype (Figure 1), we found that the regression lines by GSTM1 genotype were somewhat different but did not reach statistical significance $(p=0.59)$. For GSTT1 genotype, we observed no significant difference $(p=0.91)$.

As shown in Table 3, maternal blood $\mathrm{Hg}$ in late pregnancy and $\mathrm{Hg}$ in cord blood were significantly higher in women with a higher educational level. Hg concentration during late pregnancy was higher in pregnant women who ate $>150 \mathrm{~g}$ fish per day. However, we found no difference in $\mathrm{Hg}$ level according to GSTM1 or GSTT1 genotype.

Table 4 shows the relationship between $\mathrm{Hg}$ level and birth weight according to
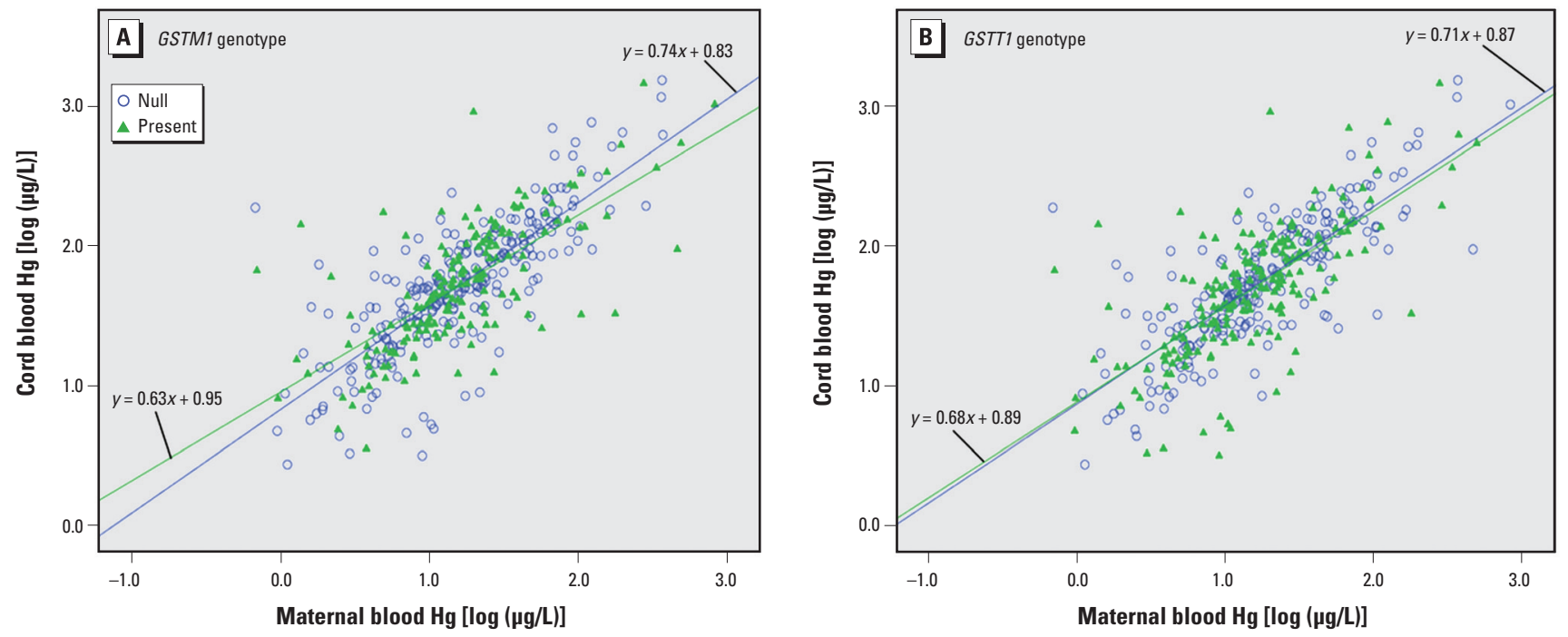

Figure 1. Relationship between cord blood and maternal blood Hg by GSTM1 ( $A$ ) and GSTT1 (B) genotype. 
GSTM1/GSTT1 genotype. Overall, we found an inverse relationship between birth weight and maternal and cord blood $\mathrm{Hg}$ levels. The birth weight of newborns whose mothers had the GSTM1 null type decreased with increasing cord blood $\mathrm{Hg}$ level. Birth weight also decreased with increasing maternal $\mathrm{Hg}$ level in late pregnancy in newborns whose mothers had the GSTT1 null type. However, we found no significant inverse relationship between $\mathrm{Hg}$ level and birth weight in the GSTM1 and GSTT1 present genotypes. In early pregnancy, the birth weight decreased with increasing $\mathrm{Hg}$ level but not significantly, and GSTM1 or GSTT1 genotype did not affect the relationship. We found similar results that did not reach statistical significance when we carried out multivariate analysis after excluding the preterm births.

Table 3. Distribution of maternal and cord blood $\mathrm{Hg}$ concentration $(\mu \mathrm{g} / \mathrm{L})$ by maternal characteristics.

\begin{tabular}{|c|c|c|c|c|c|c|}
\hline \multirow[b]{3}{*}{ Characteristic } & \multicolumn{4}{|c|}{ Maternal blood Hg } & & \\
\hline & \multicolumn{2}{|c|}{ During early pregnancy } & \multicolumn{2}{|c|}{ During late pregnancy } & \multicolumn{2}{|c|}{ Cord blood $\mathrm{Hg}$} \\
\hline & Median & $p$-Value ${ }^{a}$ & Median & $p$-Value ${ }^{a}$ & Median & $p$-Value ${ }^{a}$ \\
\hline \multicolumn{7}{|l|}{ Age (years) } \\
\hline$<30$ & 3.96 & 0.85 & 3.20 & 0.13 & 5.62 & 0.26 \\
\hline 30 to $<35$ & 3.84 & & 3.35 & & 5.64 & \\
\hline$\geq 35$ & 3.57 & & 3.04 & & 5.06 & \\
\hline \multicolumn{7}{|c|}{ BMl at prepregnancy $\left(\mathrm{kg} / \mathrm{m}^{2}\right)$} \\
\hline$<18.5$ & 3.54 & 0.66 & 3.83 & 0.28 & 6.03 & 0.50 \\
\hline 18.5 to $<23.0$ & 3.66 & & 3.19 & & 5.48 & \\
\hline$\geq 23.0$ & 4.13 & & 3.37 & & 5.74 & \\
\hline \multicolumn{7}{|c|}{ Education (years) } \\
\hline$<12$ & 3.66 & 0.27 & 3.09 & 0.04 & 5.01 & $<0.01$ \\
\hline$\geq 12$ & 3.89 & & 3.38 & & 5.78 & \\
\hline \multicolumn{7}{|c|}{ Fish consumption (g/day) } \\
\hline$\leq 150$ & 3.76 & 0.32 & 3.16 & 0.03 & 5.54 & 0.18 \\
\hline$>150$ & 4.27 & & 3.95 & & 5.75 & \\
\hline \multicolumn{7}{|l|}{ GSTM1 } \\
\hline Present & 3.90 & 0.77 & 3.30 & 0.90 & 5.53 & 0.88 \\
\hline Null & 3.69 & & 3.21 & & 5.58 & \\
\hline \multicolumn{7}{|l|}{ GSTT1 } \\
\hline Present & 3.95 & 0.70 & 3.22 & 0.53 & 5.54 & 0.42 \\
\hline Null & 3.67 & & 3.26 & & 5.56 & \\
\hline
\end{tabular}

Table 5 shows joint effect estimates for $\mathrm{Hg}$ level and GSTM1/GSTT1 polymorphisms. Subjects whose $\mathrm{Hg}$ levels in late pregnancy exceeded the 90th percentile had significantly lower birth weight compared with subjects with $\mathrm{Hg}$ levels less than the 90th percentile. The interaction term for GSTMI and $\mathrm{Hg}$ level in early pregnancy was significant, whereas the interaction of GSTM1 and $\mathrm{Hg}$ level during late pregnancy was marginally significant. We also found that the interaction between cord blood $\mathrm{Hg}$ and GSTM1 genotype was marginally significant. On the other hand, the interaction between $\mathrm{Hg}$ level in early or late pregnancy and GSTT1 genotype was not significant. In addition, we found no significant interactions between cord blood $\mathrm{Hg}$ and

GSTT1 genotype. 
the left could cause a public health burden, which would be enhanced among these susceptible groups.

To the best of our knowledge, this is the first study to demonstrate gene-environment interactions in the association between $\mathrm{Hg}$ exposure and birth weight.

In this study, the GMs of the total $\mathrm{Hg}$ concentrations in the maternal blood during early and late pregnancy were $3.67 \mu \mathrm{g} / \mathrm{L}$ and $3.30 \mu \mathrm{g} / \mathrm{L}$, respectively. In contrast, the GM of $\mathrm{Hg}$ levels in cord blood was $5.53 \mu \mathrm{g} / \mathrm{L}$, which is higher than that of the maternal blood. The blood total $\mathrm{Hg}$ concentration in this study was relatively high compared with concentrations reported in other studies. In a recent study performed in the United States, Lederman et al. (2008) reported a GM total $\mathrm{Hg}$ level for maternal and cord blood of $1.6 \mu \mathrm{g} / \mathrm{L}$ and $4.44 \mu \mathrm{g} / \mathrm{L}$, respectively. Among pregnant women living in Quebec, the GM of blood total $\mathrm{Hg}$ level at delivery was $0.48 \mu \mathrm{g} / \mathrm{L}$ (Morrissette et al. 2004). Jedrychowski et al. (2007) reported an average total Hg concentration of $0.83 \mu \mathrm{g} / \mathrm{L}$ in mothers at delivery and $1.09 \mu \mathrm{g} / \mathrm{L}$ in newborns. In contrast, the GM of the blood total $\mathrm{Hg}$ concentration in pregnant women in Taiwan and Greenland was $8.6 \mu \mathrm{g} / \mathrm{L}$ and $12.8 \mu \mathrm{g} / \mathrm{L}$, respectively (Bjerregaard and Hansen 2000; Hsu et al. 2007). In the present study, $13.2 \%$ of the maternal blood $\mathrm{Hg}$ levels during late pregnancy exceeded $5.8 \mu \mathrm{g} / \mathrm{L}$, which is the value recommended by the U.S. Environmental Protection Agency to monitor $\mathrm{Hg}$ concentrations in blood. Our finding of the higher $\mathrm{Hg}$ concentrations in the cord blood than in the maternal blood was consistent with previous studies. This finding can partly be explained by the fact that $\mathrm{Hg}$ is transferred to the fetus through the placenta (Kajiwara et al. 1996; Morrissette et al. 2004) and has a high affinity to fetal hemoglobin (Hsu et al. 2007; Iyengar and Rapp 2001), which is consistent with the observation that newborns show a larger hematocrit than do their mothers (Stern and Smith 2003).

The relationship between $\mathrm{Hg}$ exposure and pregnancy outcomes is controversial, particularly for low birth weight. Only a few studies have examined these associations, and the published results are inconsistent. Sikorski et al. (1986) assessed the concentration of total $\mathrm{Hg}$ in the hair of newborns and found that infants with a scalp hair $\mathrm{Hg}$ concentration of $>0.07 \mathrm{mg} / \mathrm{kg}$ had a 361-g lower mean birth weight than did infants with lower concentrations. In Greenland, Foldspang and Hansen (1990) reported that higher maternal and offspring $\mathrm{MeHg}$ blood concentrations were associated with low mean birth weight. A German study found that exposure to $\mathrm{Hg}$ among occupational workers is associated with growth retardation of their newborns (Seidler et al. 1999). These findings are in agreement with the present result that total $\mathrm{Hg}$ in maternal and cord blood is associated with decreased birth weight. In addition, in animal studies,

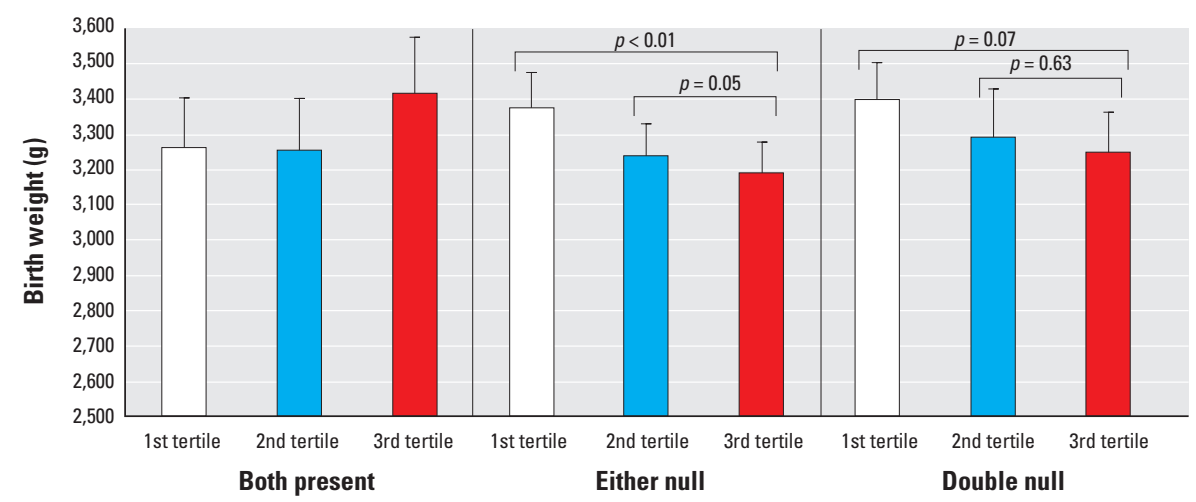

Figure 2. Estimated mean birth weight by maternal $\mathrm{Hg}$ tertile and GSTM1/GSTT1 genotypes. Least-square means were estimated in the generalized linear model, adjusting for gestational age, prepregnancy BMI, weight gain during pregnancy, maternal age, education, infant sex, and parity. The average $\mathrm{Hg}$ level during pregnancy was divided into tertiles, and genotype was classified by combination of GSTM1 and GSTT1 genotypes.

Table 5. Regression model testing main and interactive effects of blood $\mathrm{Hg}(\mu \mathrm{g} / \mathrm{L})$ and GSTM1 or GSTT1 genotype on birth weight.

\begin{tabular}{|c|c|c|c|c|c|c|}
\hline \multirow[b]{2}{*}{ Model } & \multicolumn{2}{|c|}{ Early pregnancy } & \multicolumn{2}{|c|}{ Late pregnancy } & \multicolumn{2}{|c|}{ Cord blood } \\
\hline & $\beta$ & $p$-Value & $\beta$ & $p$-Value & $\beta$ & $p$-Value \\
\hline \multicolumn{7}{|l|}{ Model 1: GSTM1 interaction } \\
\hline Hg level ( $\geq$ 90th vs. $<90$ th) & -114.9 & 0.18 & -197.6 & 0.01 & -215.4 & 0.007 \\
\hline Interaction term of GSTM $1^{*} \mathrm{Hg}$ level & 298.5 & 0.04 & 243.8 & 0.06 & 231.3 & 0.07 \\
\hline \multicolumn{7}{|l|}{ Model 2: GSTT1 interaction } \\
\hline Hg level ( $\geq 90$ th vs $<90$ th) & -73.7 & 0.40 & -80.6 & 0.34 & -64.8 & 0.43 \\
\hline
\end{tabular}

Adjusted for gestational age, prepregnancy BMI, maternal age, mother's educational level, infant sex, parity, and weight gain during pregnancy.

Table 6. Association of combined GSTM1 and GSTT1 genotype and $\mathrm{Hg}$ level with birth weight.

\begin{tabular}{|c|c|c|c|c|c|c|c|}
\hline \multirow{2}{*}{$\begin{array}{l}\text { Exposure period of total } \mathrm{Hg} \\
\text { level (log scale of } \mu \mathrm{g} / \mathrm{L})\end{array}$} & \multirow{2}{*}{ Genotype } & \multirow{2}{*}{\multicolumn{2}{|c|}{ Unadjusted }} & \multicolumn{4}{|c|}{ Adjusted $^{a}$} \\
\hline & & & & \multicolumn{2}{|c|}{ Full sample } & \multicolumn{2}{|c|}{ Subsample excluding preterm births } \\
\hline Early pregnancy & $\begin{array}{l}\text { Both present }^{b} \\
\text { Either null } \\
\text { Double null } \\
\end{array}$ & $\begin{array}{l}130.7 \\
-27.3 \\
-27.6\end{array}$ & $\begin{array}{l}-49.8 \text { to } 311.1 \\
-141.0 \text { to } 86.5 \\
-143.9 \text { to } 88.8\end{array}$ & $\begin{array}{r}39.6 \\
-129.4 \\
-39.9\end{array}$ & $\begin{array}{l}-144.8 \text { to } 224.0 \\
-232.8 \text { to }-26.1 \\
-155.4 \text { to } 75.7\end{array}$ & $\begin{array}{r}39.6 \\
-99.2 \\
-26.0\end{array}$ & $\begin{array}{l}-144.8 \text { to } 224.0 \\
-206.7 \text { to } 8.4 \\
-142.6 \text { to } 90.5\end{array}$ \\
\hline Late pregnancy & $\begin{array}{l}\text { Both present } \\
\text { Either null } \\
\text { Double null } \\
{ }^{d}\end{array}$ & $\begin{array}{l}104.4 \\
-33.11 \\
-62.8\end{array}$ & $\begin{array}{l}-82.1 \text { to } 290.9 \\
-157.1 \text { to } 90.9 \\
-169.2 \text { to } 43.6\end{array}$ & $\begin{array}{r}46.2 \\
-74.8 \\
-102.8\end{array}$ & $\begin{array}{l}-134.7 \text { to } 227.1 \\
-186.6 \text { to } 37.0 \\
-205.4 \text { to }-0.2\end{array}$ & $\begin{array}{r}46.2 \\
-29.9 \\
-89.1\end{array}$ & $\begin{array}{l}-134.7 \text { to } 227.1 \\
-143.9 \text { to } 84.1 \\
-193.2 \text { to } 15.1\end{array}$ \\
\hline
\end{tabular}

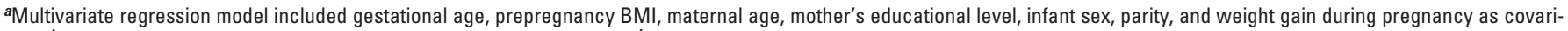
ates. ${ }^{b}$ Both GSTM1 and GSTT1 is present. ${ }^{c}$ Either GSTM1 or GSTT1 is null. ${ }^{d}$ Both GSTM1 and GSTT1 are null. 
neonates from dams exposed to higher levels of metallic $\mathrm{Hg}\left(\mathrm{Hg}^{0}\right)$ weigh significantly less than the controls at birth (Morgan et al. 2002), and average weights of the pups at birth were $7-10 \%$ lower in groups treated with $\mathrm{MeHg}$ during gestation compared with controls (Beyrouty and Chan 2006).

However, some studies do not support the relationship between $\mathrm{Hg}$ exposure and birth weight. In a fishing community in Denmark, total $\mathrm{Hg}$ concentration in cord blood was not correlated with birth weight (Grandjean et al. 2001). Lederman et al. (2008) found that total $\mathrm{Hg}$ in neither cord nor maternal blood was related to newborn size. A recent British study showed that total $\mathrm{Hg}$ levels in umbilical cord tissue were not related to birth weight (Daniels et al. 2007). This disparity among studies might be due to differences in genetic predisposition, dietary patterns, and environmental factors (Lederman et al. 2008).

In the present study we investigated the gene-environment interactions between blood $\mathrm{Hg}$ and GST polymorphisms on birth weight. The gene-environment interaction between $\mathrm{Hg}$ level in early pregnancy and GSTM1 polymorphism was significant. We also found a marginally significant interaction with $\mathrm{Hg}$ level during late pregnancy. Because of the half-life of $\mathrm{Hg}$, these results suggest that early pregnancy exposure might be important even though most birth weight gain is attained in the third trimester. Although we performed stratified analysis according to GSTM1/GSTT1 genotype, the decrease in birth weight was significantly associated with cord blood $\mathrm{Hg}$ levels in mothers who were GSTM1 null as well as with maternal blood $\mathrm{Hg}$ level during late pregnancy in mothers who were GSTT1 null. After excluding preterm births $(3.4 \%)$ from the data, we found similar trends, but statistical significance was not sustained. To date, however, there are no reports of the relationship between $\mathrm{Hg}$ levels and birth weight according to GST genotype. Only a few studies observed a relationship between a GST polymorphism and $\mathrm{Hg}$ concentration. Gundacker et al. (2007) found that a double-deleted genotype for GSTT1 and GSTM1 was associated with a higher hair $\mathrm{Hg}$ concentration. In this study, we found no significant difference in the maternal $\mathrm{Hg}$ levels in women with either a GSTM1 or a GSTT1 polymorphism. Similarly, Custodio et al. (2004) reported that GSTM1 and GSTT1 polymorphisms did not affect erythrocyte $\mathrm{Hg}$ concentrations.

The mechanism for how a GST polymorphism modifies the relationship between $\mathrm{Hg}$ level and birth weight has not been elucidated. $\mathrm{Hg}$ has a high affinity for GSH, and binding and dissociation of the GSH-Hg complex are believed to control the movement of $\mathrm{Hg}$ as well as its toxic effects in the body (Clarkson
1997). Among the GSH-related enzymes, GSTs may catalyze the intracellular binding reaction of $\mathrm{Hg}$ with GSH (Engström et al. 2008; Gundacker et al. 2007). In particular, the roles of the two GST genes, GSTT1 and GSTM1, are important in Hg metabolism because the deletion type of GSTM1/ GSTT1 reduces catalytic activity, leading to the slower elimination of $\mathrm{Hg}$ (Custodio et al. 2005; Hayes and Strange 2000). In the present study we found that the total $\mathrm{Hg}$ level in maternal blood during late pregnancy or in cord blood was associated more significantly with a decreased birth weight in women with the double-deleted genotype than in women with the intact genotype or one of the null genotypes. The double-deletion polymorphism might be more important because this combination impairs the ability for detoxification more and increases the susceptibility to $\mathrm{Hg}$ exposure (Gundacker et al. 2007).

Another plausible mechanism is a decrease in birth weight via oxidative stress according to $\mathrm{Hg}$ exposure. $\mathrm{Hg}$ has been reported to cause oxidative stress, which may lead to lipid peroxidation and the generation of reactive oxygen species (Huang et al. 2008; Pinheiro et al. 2008). Hui et al. (2001) suggested that heavy metals, such as $\mathrm{Hg}$ and cadmium, might induce oxidative stress caused by changes in the GSH and/or ATP metabolism. Also, pregnancy is a condition that favors oxidative stress, mainly due to the mitochondriarich placenta, which may also be enhanced by the presence of metal toxins (Casanueva and Viteriy 2003; Chen and Lin 1998). However, we found no effect of GSTM1/GSTT1 genotype on the relationship between maternal and cord blood $\mathrm{Hg}$. This implies that an effect of GSTM1/GSTT1 on the association between $\mathrm{Hg}$ and birth weight might be mediated by genetic modification on the oxidative stress level induced by $\mathrm{Hg}$ rather than an effect of GSTM1/GSTT1 on the metabolism of $\mathrm{Hg}$.

The major strengths of this study are the prospective cohort design, the collection of more reliable data from the medical records, and adjustment for important confounders potentially affecting $\mathrm{Hg}$ exposure and birth weight. We measured $\mathrm{Hg}$ levels in maternal and cord blood, which reflects the changes in recent exposure (Foldspang and Hansen 1990; Grandjean et al. 2001; Lucas et al. 2004). Nevertheless, $\mathrm{Hg}$ concentrations assessed in the first and third trimesters could reflect the exposure during early and late pregnancy because the mean half-life of $\mathrm{MeHg}$ in blood is approximately 45 days (range, 20-70 days) (Clarkson 1993; Smith and Farris 1996). Information on fish consumption was collected using 24-hr recall, which can result in recall bias and may not reflect dietary intake during the entire period of pregnancy. However, there did not appear to be any differential recall bias, because the dietary survey was carried out before the pregnancy outcome (Xue et al. 2007). In this study, the total $\mathrm{Hg}$ level in maternal and cord blood was assessed. Hence, the effect of specific forms of $\mathrm{Hg}$ could not be investigated. Although the blood $\mathrm{Hg}$ level did not consist entirely of $\mathrm{MeHg}$, it is generally used to represent $\mathrm{MeHg}$ exposure because total $\mathrm{Hg}$ concentrations in whole blood reflect exposure to organic $\mathrm{Hg}$, predominantly $\mathrm{MeHg}$ (Sanzo et al. 2001). Furthermore, cord blood $\mathrm{Hg}$ was almost entirely $\mathrm{MeHg}$ because the placenta does not present a barrier to $\mathrm{MeHg}$ (Kelman et al. 1982).

This study showed that GST gene polymorphisms may play important roles in the relationship between $\mathrm{Hg}$ level and birth weight. Although a single defective gene might be associated with decreased birth weight, these results suggest that a combined genotype of GSTM1 and GSTT1 should be considered. Therefore, these findings highlight the need for new policy guidelines to reduce the level of $\mathrm{Hg}$ exposure in high-risk groups, particularly pregnant women with genetic susceptibility.

\section{REFERENCES}

Ballatori N. 2002. Transport of toxic metals by molecular mimicry. Environ Health Perspect 110(suppl 5):689-694.

Ballatori N, Clarkson TW. 1985. Biliary secretion of glutathione and of glutathione-metal complexes. Fundam Appl Toxicol 5:816-831.

Beyrouty P, Chan HM. 2006. Co-consumption of selenium and vitamin $\mathrm{E}$ altered the reproductive and developmental toxicity of methylmercury in rats. Neurotoxicol Teratol 28:49-58.

Bjerregaard P, Hansen JC. 2000. Organochlorines and heavy metals in pregnant women from the Disko Bay area in Greenland. Sci Total Environ 245(1-3):195-202

Brodsky JB, Cohen EN, Whitcher C, Brown BW Jr, Wu ML. 1985. Occupational exposure to mercury in dentistry and pregnancy outcome. J Am Dent Assoc 111:779-780.

Casanueva E, Viteriy FE. 2003. Iron and oxidative stress in pregnancy. J Nutr 133:1700S-1708S.

Castoldi AF, Coccini T, Ceccatelli S, Manzo L. 2001. Neurotoxicity and molecular effects of methylmercury. Brain Res Bull 55:197-203.

Chen CY, Lin TH. 1998. Nickel toxicity to human term placenta: in vitro study on lipid peroxidation. J Toxicol Environ Health A 54:37-47.

Clarkson TW. 1993. Mercury: major issues in environmental health. Environ Health Perspect 100:31-38.

Clarkson TW. 1997. The toxicology of mercury. Crit Rev Clin Lab Sci 34:369-403.

Counter SA, Buchanan LH. 2004. Mercury exposure in children: a review. Toxicol Appl Pharmacol 198:209-230.

Custodio HM, Broberg K, Wennberg M, Jansson JH, Vessby B, Hallmans $\mathrm{G}$, et al. 2004. Polymorphisms in glutathione-related genes affect methylmercury retention. Arch Environ Health 59:588-595.

Custodio HM, Harari R, Gerhardsson L, Skerfving S, Broberg K. 2005. Genetic influences on the retention of inorganic mercury. Arch Environ Occup Health 60:17-23.

Daniels JL, Rowland AS, Longnecker MP, Crawford P, Golding J; ALSPAC Study Team. 2007. Maternal dental history, child's birth outcome and early cognitive development. Paediatr Perinat Epidemiol 21:448-457.

Dusinská M, Ficek A, Horská A, Raslová K, Petrovská H, Vallová B, et al. 2001. Glutathione $S$-transferase polymorphisms influence the level of oxidative DNA damage and antioxidant protection in humans. Mutat Res 482:47-55.

Engström K, Strömberg U, Lundh T, Johansson I, Vessby B, Hallmans $\mathrm{G}$, et al. 2008. Genetic variation in glutathione- 
related genes and body burden of methylmercury. Environ Health Perspect 116:734-739.

Foldspang A, Hansen JC. 1990. Dietary intake of methylmercury as a correlate of gestational length and birth weight among newborns in Greenland. Am J Epidemiol 132:310-317.

Fredriksson A, Gårdlund AT, Bergman K, Oskarsson A, Ohlin B, Danielsson $B$, et al. 1993. Effects of maternal dietary supplementation with selenite on the postnatal development of rat offspring exposed to methylmercury in-utero. Pharmacol Toxicol 72:377-382.

Grandjean P, Bjerve KS, Weihe P, Steuerwald U. 2001. Birthweight in a fishing community: significance of essential fatty acids and marine food contaminants. Int $\mathrm{J}$ Epidemiol 30:1272-1278.

Gundacker C, Komarnicki G, Jagiello P, Gencikova A, Dahmen N, Wittmann KJ, et al. 2007. Glutathione-Stransferase polymorphism, metallothionein expression, and mercury levels among students in Austria. Sci Total Environ 385:37-47.

Hayes JD, Strange RC. 2000. Glutathione $S$-transferase polymorphisms and their biological consequences. Pharmacology 61:154-166.

Hsu CS, Liu PL, Chien LC, Chou SY, Han BC. 2007. Mercury concentration and fish consumption in Taiwanese pregnant women. BJOG 114:81-85.

Huang CF, Hsu CJ, Liu SH, Lin-Shiau SY. 2008. Neurotoxicological mechanism of methylmercury induced by low-dose and long-term exposure in mice: oxidative stress and down-regulated $\mathrm{Na}+/ \mathrm{K}(+)$-ATPase involved. Toxicol Lett 176:188-197.

Hui YY, McAmis WC, Baynes JW, Schaeffer RC Jr, Wolf MB. 2001. Effect of advanced glycation end products on oxidative stress in endothelial cells in culture: a warning on the use of cells studied in serum-free media. Diabetologia 44:1310-1317.

Hussain S, Rodgers DA, Duhart HM, Ali SF. 1997. Mercuric chloride-induced reactive oxygen species and its effect on antioxidant enzymes in different regions of rat brain. J Environ Sci Health B 32:395-409.

lyengar GV, Rapp A. 2001. Human placentaas a "dual" biomarker for monitoring fetal and maternal environment with special reference to potentially toxic trace elements. Part 3: toxic trace elements in placenta and placenta as a biomarker for these elements. Sci Total Environ 280:221-238. Jain M, Kumar S, Rastogi N, Lal P, Ghoshal UC, Tiwari A, et al.
2006. GSTT1, GSTM1 and GSTP1 genetic polymorphisms and interaction with tobacco, alcohol and occupational exposure in esophageal cancer patients from North India. Cancer Lett 242:60-67.

Jedrychowski W, Jankowski J, Flak E, Skarupa A, Mroz E Sochacka-Tatara E, et al. 2006. Effects of prenatal exposure to mercury on cognitive and psychomotor function in one-year-old infants: epidemiologic cohort study in Poland. Ann Epidemiol 16:439-447.

Jedrychowski W, Perera F, Rauh V, Flak E, Mróz E, Pac A, et al. 2007. Fish intake during pregnancy and mercury level in cord and maternal blood at delivery: an environmenta study in Poland. Int J 0ccup Med Environ Health 20:31-37.

Kajiwara Y, Yasutake A, Adachi T, Hirayama K. 1996. Methylmercury transport across the placenta via neutral amino acid carrier. Arch Toxicol 70:310-314.

Kelman BJ, Walter BK, Sasser LB. 1982. Fetal distribution of mercury following introduction of methylmercury into porcine maternal circulation. J Toxicol Environ Health 10:191-200.

Kim YJ, Park HS, Park MH, Suh SH, Pang MG. 2005. Oxidative stress-related gene polymorphism and the risk of preeclampsia. Eur J Obstet Gynecol Reprod Biol 19:42-46.

Lederman SA, Jones RL, Caldwell KL, Rauh V, Sheets SE, Tang D, et al. 2008. Relation between cord blood mercury levels and early child development in a World Trade Center cohort. Environ Health Perspect 116:1085-1091.

Lucas M, Dewailly E, Muckle G, Ayotte P, Bruneau S, Gingras S, et al. 2004. Gestational age and birth weight in relation to n-3 fatty acids among Inuit (Canada). Lipids 39:617-626.

Lund BO, Miller DM, Woods JS. 1993. Studies on Hg(II)-induced $\mathrm{H}_{2} \mathrm{O}_{2}$ formation and oxidative stress in vivo and in vitro in rat kidney mitochondria. Biochem Pharmacol 45:2017-2024.

Marques RC, Dórea JG, Bernardi JV, Bastos WR, Malm 0. 2008. Maternal fish consumption in the nutrition transition of the Amazon Basin: growth of exclusively breastfed infants during the first 5 years. Ann Hum Biol 35:363-377.

Morgan DL, Chanda SM, Price HC, Fernando R, Liu J, Brambila $E$, et al. 2002. Disposition of inhaled mercury vapor in pregnant rats: maternal toxicity and effects on developmental outcome. Toxicol Sci 66:261-273.

Morrissette J, Takser L, St-Amour G, Smargiassi A, Lafond J Mergler D. 2004. Temporal variation of blood and hair mercury levels in pregnancy in relation to fish consumption history in a population living along the St. Lawrence River. Environ Res 95:363-374.
Oken E, Bellingerb DC. 2008. Fish consumption, methylmercury and child neurodevelopment. Curr Opin Pediatr 20:178-183.

Park EY, Hong YC, Lee KH, Im MW, Ha E, Kim YJ, et al. 2008. Maternal exposure to environmental tobacco smoke, GSTM1/T1 polymorphisms and oxidative stress. Reprod Toxicol 26(3-4):197-202.

Pinheiro MC, Macchi BM, Vieira JL, Oikawa T, Amoras WW, Guimarães GA, et al. 2008. Mercury exposure and antioxidant defenses in women: a comparative study in the Amazon. Environ Res 107:53-59.

Sanzo JM, Dorronsoro M, Amiano $P$, Amurrio $A$ Aguinagalde FX, Azpiri MA; EPIC Group of Spain. 2001. Estimation and validation of mercury intake associated with fish consumption in an EPIC cohort of Spain. Public Health Nutr 4:981-988.

Schneider J, Bernges U, Philipp M, Woitowitz HJ. 2004. GSTM1, GSTT1, and GSTP1 polymorphism and lung cancer risk in relation to tobacco smoking. Cancer Lett 208:65-74.

Seidler A, Raum E, Arabin B, Hellenbrand W, Walter U, Schwartz FW. 1999. Maternal occupational exposure to chemical substances and the risk of infants small-forgestational-age. Am J Ind Med 36:213-222.

Sikorski R, Juszkiewicz T, Paszkowski T, SzprengierJuszkiewicz T. 1987. Women in dental surgeries: reproductive hazards in occupational exposure to metallic mercury. Int Arch Occup Environ Health 59:551-557.

Sikorski R, Paszkowski T, Szprengier-Juszkiewicz T. 1986. Mercury in neonatal scalp hair. Sci Total Environ 57:105-110.

Smith JC, Farris FF. 1996. Methyl mercury pharmacokinetics in man: a reevaluation. Toxicol Appl Pharmacol 137:245-252.

Stern AH, Smith AE. 2003. An assessment of the cord blood: maternal blood methylmercury ratio: implications for risk assessment. Environ Health Perspect 111:1465-1470.

Trasande L, Landrigan PJ, Schechter C. 2005. Public health and economic consequences of methyl mercury toxicity to the developing brain. Environ Health Perspect 113:590-596.

Wormhoudt LW, Commandeur JN, Vermeulen NP. 1999. Genetic polymorphisms of human $\mathrm{N}$-acetyltransferase, cytochrome P450, glutathione- $S$-transferase, and epoxide hydrolase enzymes: relevance to xenobiotic metabolism and toxicity. Crit Rev Toxicol 29:59-124.

Xue F, Holzman C, Rahbar MH, Trosko K, Fischer L. 2007. Maternal fish consumption, mercury levels, and risk of preterm delivery. Environ Health Perspect 115:42-47. 